\title{
Verifique sus conocimientos radiología de urgencias
}

JJordi Galimanya, Joan M. Estradaa y Juan Carlos Pernas ${ }^{b}$

a Enfermero. Profesor de la Escuela Universitaria de Enfermería de la Universidad de Barcelona. L'Hospitalet de Llobregat. Barcelona. España

${ }^{b}$ Médico Especialista en Radiodiagnóstico. Unidad de Radiología. Hospital Sant Pau. Barcelona. Españ

\section{INTRODUCCIÓN}

La presente entrega de la serie de Nursing sobre las pruebas complementarias es la tercera parte que complementa a las dos anteriores dedicadas a la radiología de urgencias, que trata de las situaciones clínicas y de las imágenes radiológicas más habituales obtenidas del estudio de alteraciones musculoesqueléticas.

En la presente entrega se estudian las imágenes radiológicas relacionadas con alteraciones abdominales y torácicas habituales en el servicio de urgencias. Además, se presentan imágenes de tomografía computarizada correspondientes a situaciones clínicas que, por su prevalencia, se pueden producir en urgencias.

Las tres entregas de Nursing dedicadas a las pruebas diagnósticas en el contexto de los servicios de urgencias tienen por objetivo ofrecer al profesional de enfermería la posibilidad de detectar las situaciones de riesgo a partir de las imágenes radiológicas más habituales o con una traducción radiográfica más clara y con mayor impacto en la situación clínica del paciente, siempre teniendo en cuenta que se debe considerar la clínica del paciente y disponer de una anamnesis adecuada.

De esta manera, el profesional de enfermería es capaz de valorar estas situaciones en las que la imagen radiográfica en concreto, y las pruebas complementarias en general, son vitales en la toma de decisiones de gran trascendencia clínica para el paciente en situaciones en que el tiempo de respuesta y la precisión diagnóstica adquieren relevancia.

1. La prueba radiológica de primera elección en pacientes que acuden al servicio de urgencias por dolor abdominal suele ser:

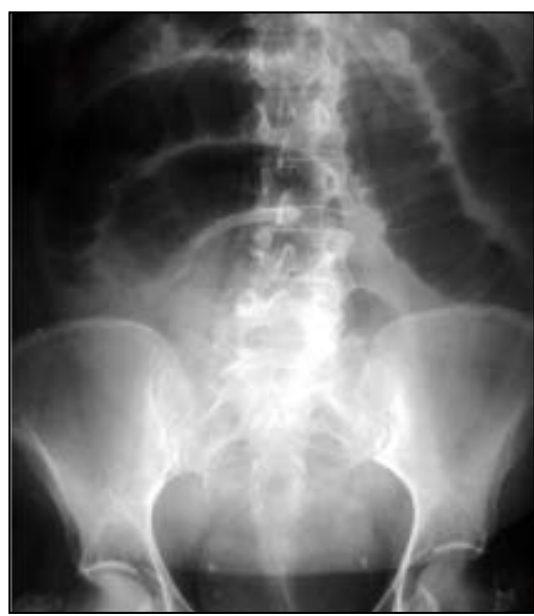

Figura 1 a. Normalmente no se realiza ninguna prueba al paciente.

b. En estos casos, la radiografía de abdomen (fig. 1) es la técnica de primera elección.

c. En estos casos, la tomografía computarizada (TC) es la técnica diagnóstica de primera elección por su elevado valor diagnóstico.

d. En estos casos, la ecografía es la técnica de primera elección.

2. En caso una radiografía de abdomen, como la que se muestra en la figura 2, en un paciente que consulta por dolor abdominal, debemos deducir:

a. Corresponde a una radiografía con una importante alteración patológica intestinal.

b. Corresponde a un paciente que recientemente se ha sometido a una técnica radiológica con contraste de bario. c. Es la imagen radiológica normal del abdomen.

d. Corresponde a un paciente que recientemente se ha sometido a una pielografía.

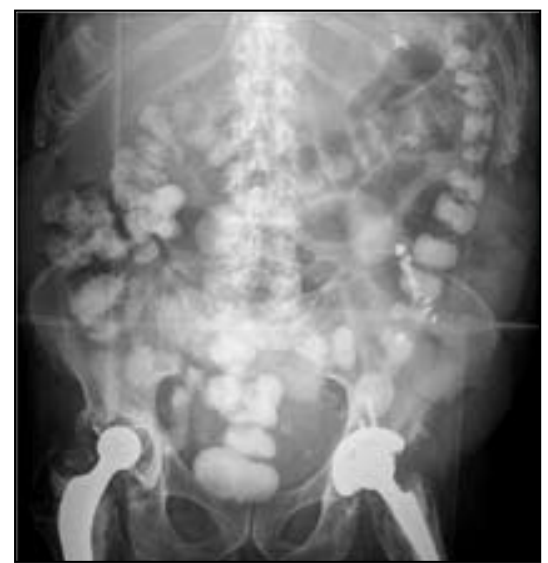

Figura 2 
3. En un paciente que consulta por dolor abdominal y con una radiografía como la de la figura 3 debemos deducir:

a. Que la radiografía se ha realizado con el paciente en bipedestación.

b. Que hay presencia de niveles hidroaéreos en epigastrio e hipocondrio izquierdo.

c. Que la imagen radiológica puede ser compatible con una obstrucción intestinal, debido a la ausencia de aire en las asas intestinales de la parte baja del abdomen.

d. Todas las respuestas son correctas.

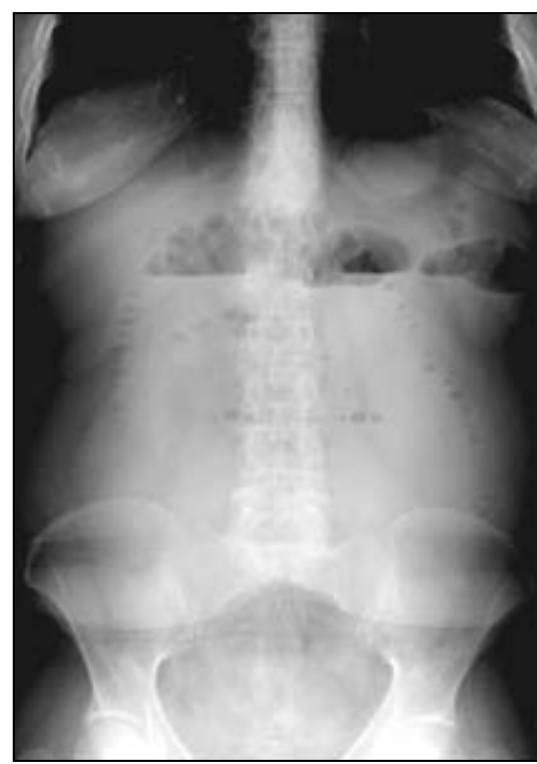

Figura 3
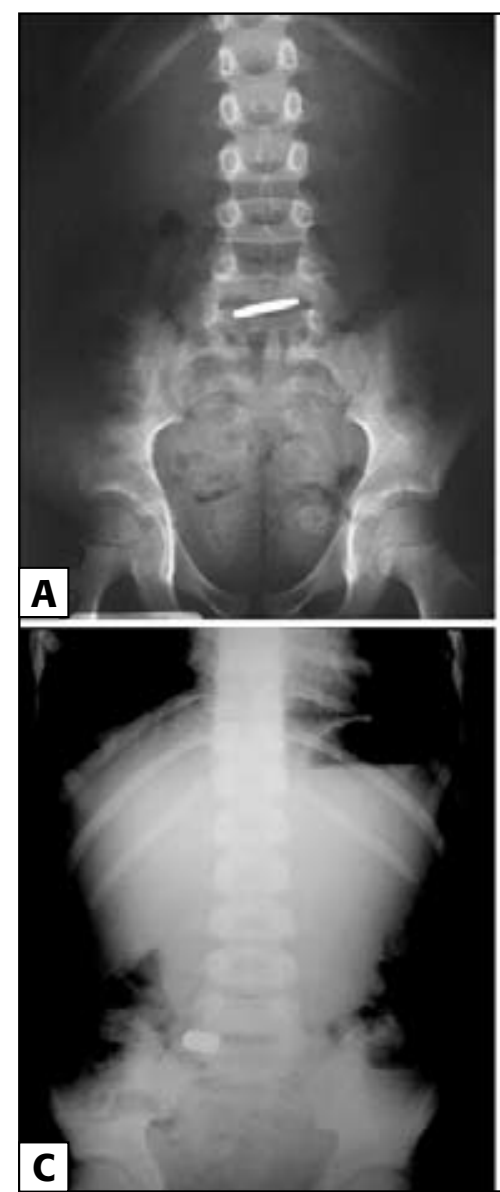

\section{B}
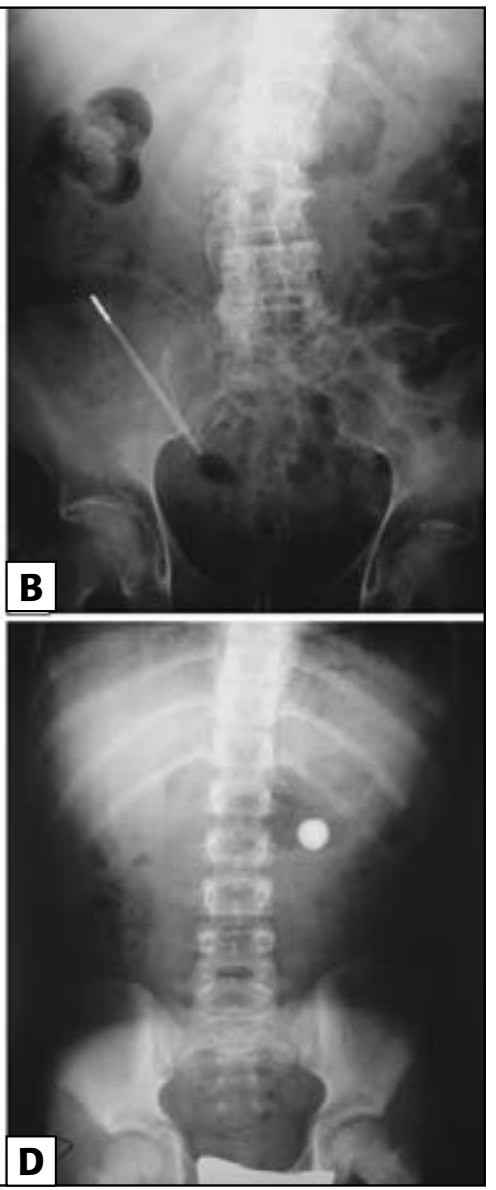

\section{Figura 4}

4. Una consulta habitual en el servicio de urgencias es la de niños que acuden por sospecha de ingestión de algún cuerpo extraño figura 4:

a. En estos casos se realiza siempre una TC de tórax y abdomen para localizar el objeto. b. En la mayoría de los casos, mediante una radiografía, se puede localizar el cuerpo extraño.

c. Inicialmente se realiza una radiografía, que normalmente se complementa con una TC.

d. Habitualmente la ecografía es más útil y menos invasiva para localizar cuerpos extraños. 


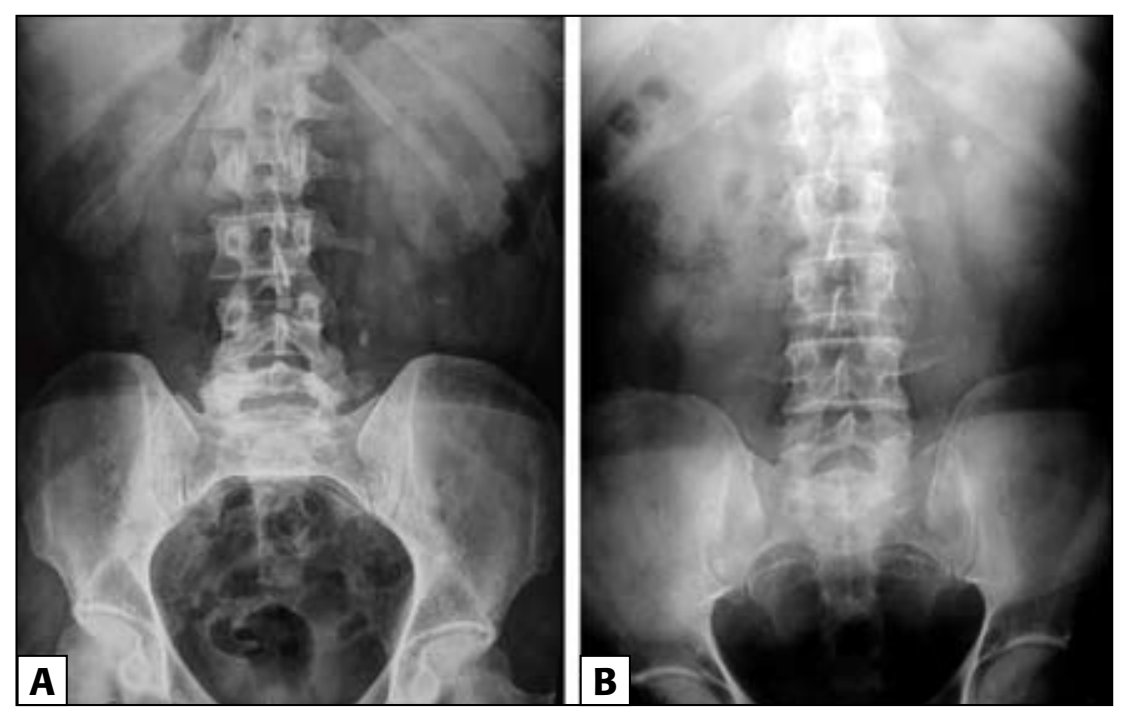

Figura 5

5. En las imágenes radiológicas que se muestran en la figura 5 se puede observar:

a. Corresponden a radiografías de abdomen con importantes niveles hidroaéreos.

b. Corresponden a radiografías con imágenes sin alteraciones de la normalidad.

c. Diversas imágenes compatibles con una obstrucción intestinal.

d. Imágenes radiológicas compatibles con calcificaciones en el tracto renal.

6. ¿Cómo actuaría en caso de que una paciente que acude al servicio de urgencias y precisara una radiografía le indicara la posibilidad de estar embarazada?

a. Indicaría a la paciente la imposibilidad absoluta de realizar la radiografía.

b. Indicaría a la paciente que no existe ninguna contraindicación para realizar la radiografía.

c. Solicitaría la prueba de embarazo, valoraría la situación clínica concreta y la necesidad de realizar la radiografía.

d. Solicitaría una prueba de embarazo, y si el test fuera positivo, en ningún caso se realizaría.

7. En la imagen radiográfica de la figura 6 se puede observar:

a. Radiografía de abdomen con ausencia de gas intestinal.

b. Radiografía de abdomen realizada a una paciente en avanzado estado de gestación.

c. Radiografía de abdomen de poca calidad técnica, difícilmente valorable.

d. Radiografía de abdomen sin alteraciones de la normalidad.

\section{Figura 6}

8. Las imágenes de la figura 7 , correspondientes a radiografías de tórax, muestran:

a. Radiografías normales, sin ninguna alteración radiológica destacable.

b. La imagen radiológica corresponde a la presencia de aire fuera de la cavidad peritoneal

c. La imagen radiológica típica en un paciente con una obstrucción intestinal.

d. Son radiografías normales. En la imagen C se observa un marcapasos.

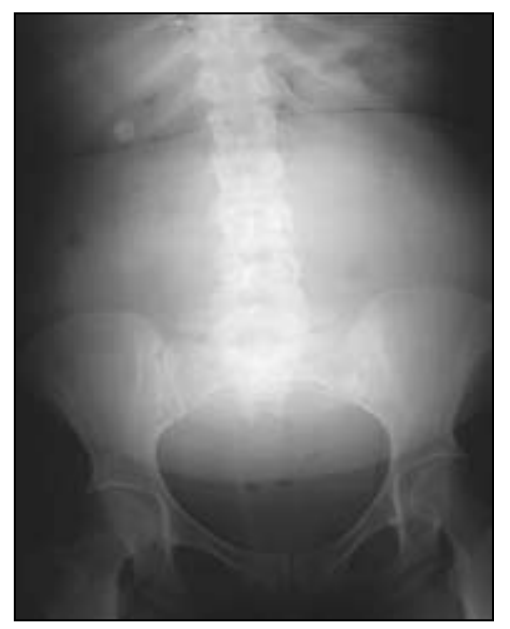

9. Según las imágenes de la figura 8 , que corresponden a radiografías de tórax en proyección anteroposterior, usted podría afirmar que:

a. Las imágenes muestran procesos condensantes en el parénquima pulmonar.

b. Las radiografías muestran imágenes radiológicas compatibles con un neumotórax.

c. Las imágenes corresponden a radiografías normales de tórax

d. Las imágenes A y C corresponden a pacientes afectados de patología pulmonar obstructiva crónica; las imágenes B y D corresponden a pacientes con infección pulmonar.

10. ¿En qué casos se pueden utilizar técnicas de diagnóstico por la imagen como mecanismo de apoyo al tratamiento en situaciones clínicas en el contexto de urgencias?

a. En pacientes que requieren intervenciones, localizaciones o en fracturas complejas.

b. En pacientes que han sufrido luxaciones para comprobar el éxito de la reducción de éstas.

c. En pacientes con fracturas desplazadas que hay que reducir.

d. Todas las respuestas son correctas.
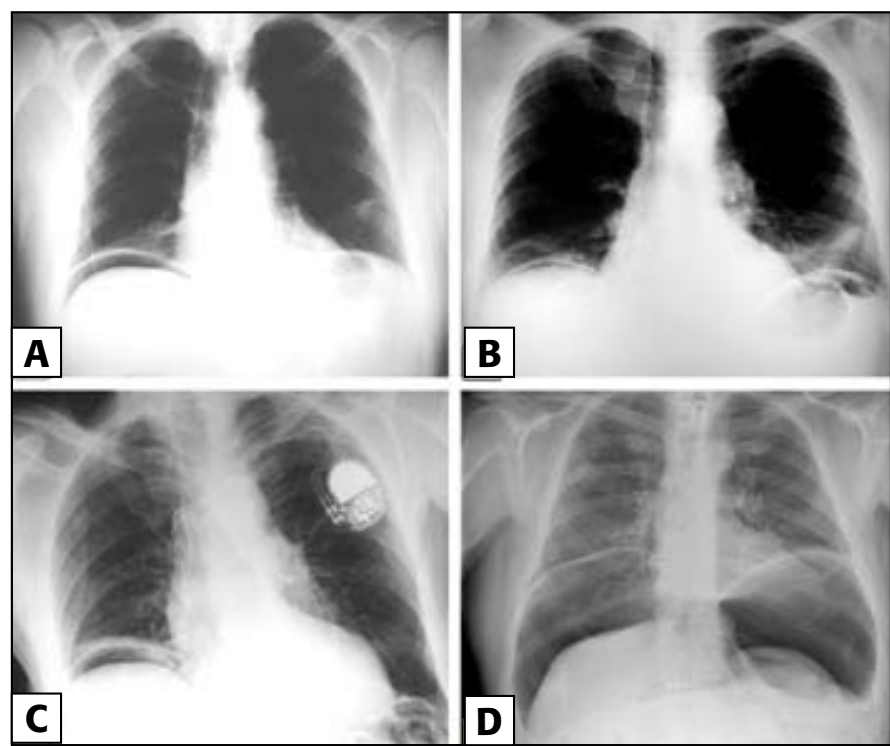

Figura 7 


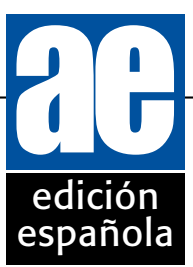

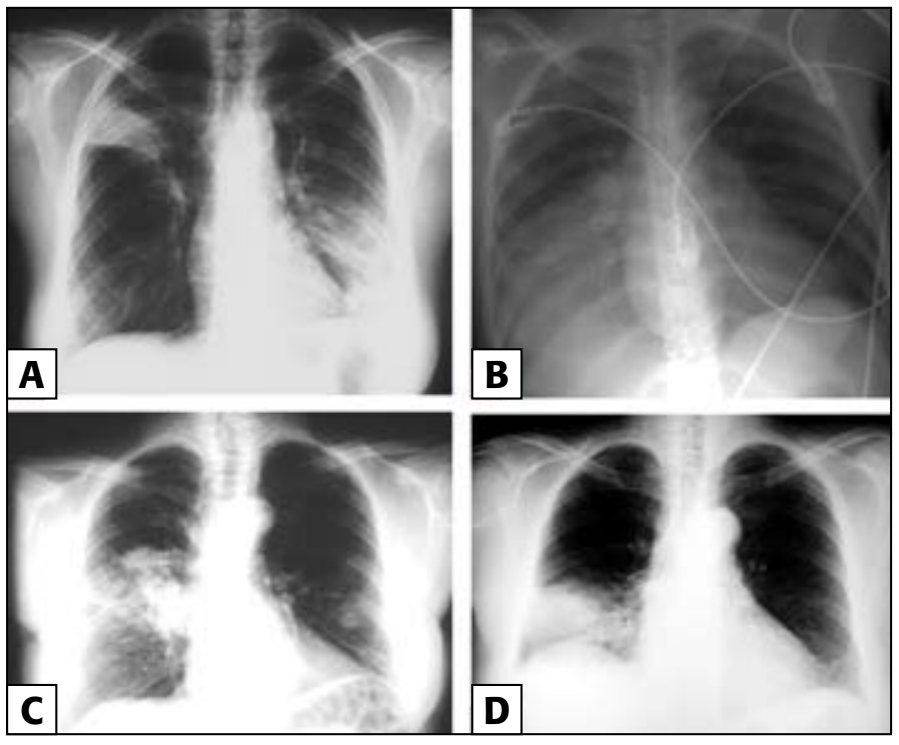

Figura 8

11. En las imágenes de la figura 9 , correspondientes a radiografías de tórax, se puede observar:

a. Son radiografías de tórax sin alteraciones destacables de la normalidad.

b. Son radiografías de pacientes con alteraciones de la columna dorsal.

c. Son radiografías compatibles con un neumotórax

d. Son radiografías de un paciente con enfermedad pulmonar obstructiva crónica (EPOC).

12. Con respecto a la preparación y las medidas previas en exploraciones radiográficas figura 10 de pacientes que acuden a urgencias, hay que tener en cuenta que:

a. Es importante retirar la ropa y los objetos que puedan dificultar o enmascarar la visualización de lesiones.
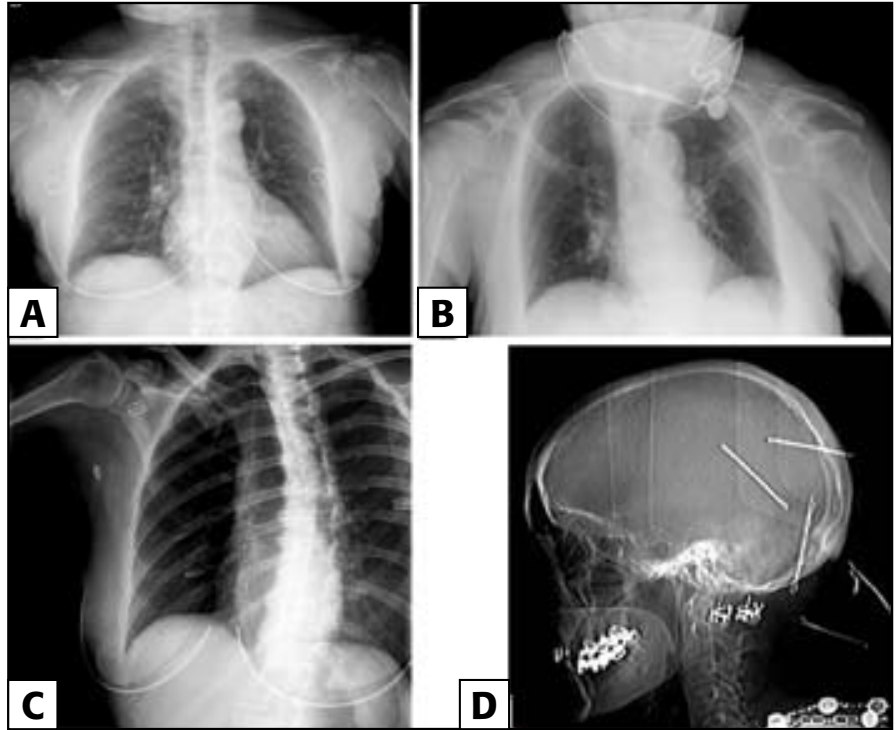

Figura 10

b. En las mujeres en edad fértil hay que preguntar por la posibilidad de embarazo.

c. Es aconsejable informar de situaciones especiales/relevantes para la realización de la radiografía (pacientes inestables, poco colaboradores, etc.)

d. Todas las respuestas son correctas.
13. ¿Cuáles son las principales indicaciones de la TC en urgencias? figura 11

a. La TC está indicada en el estudio de cráneo, tórax o abdomen que requieran tratamiento urgente.

b. La TC únicamente está indicada en el estudio de pacientes politraumatizados.
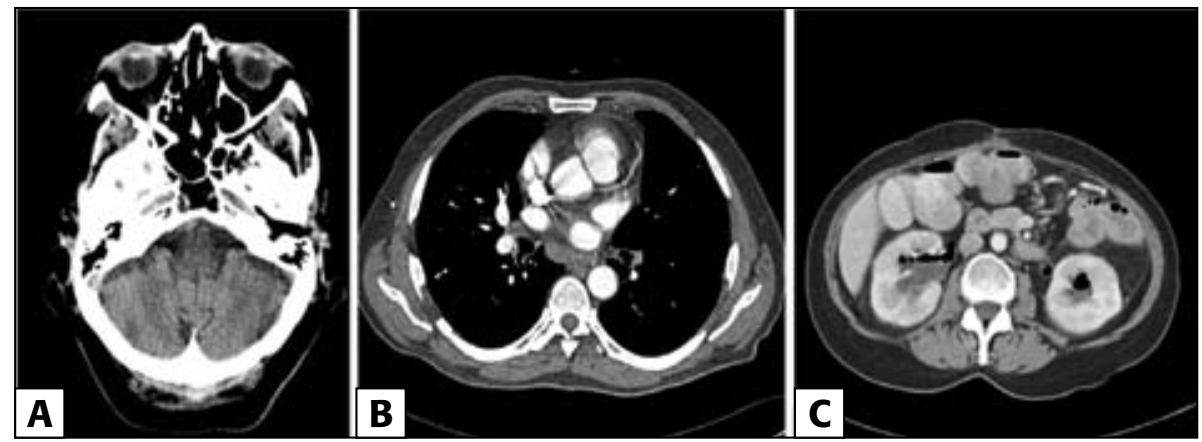

Figura 11

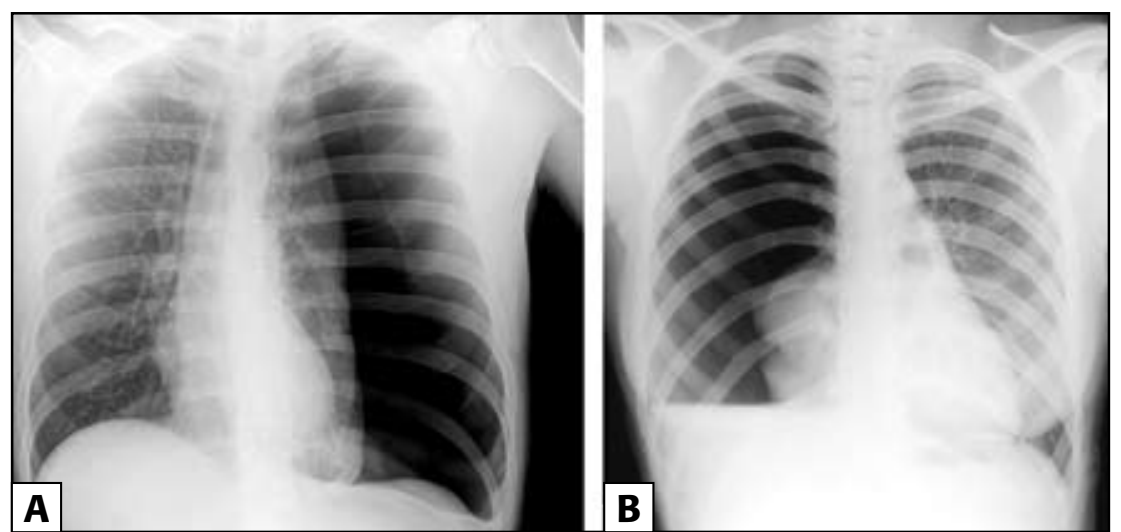

Figura 9 c. La TC está únicamente indicada en pacientes críticos.

d. La TC está indicada en estudios complejos que requieran imágenes en tres dimensiones para llegar al diagnóstico.

14. Las imágenes de la figura 12 corresponden a una TC de cráneo en la que se puede observar:

a. Cortes axiales del encéfalo con la imagen típica de masa tumoral en ambas imágenes.

b. Cortes axiales del encéfalo con imágenes compatibles con un 

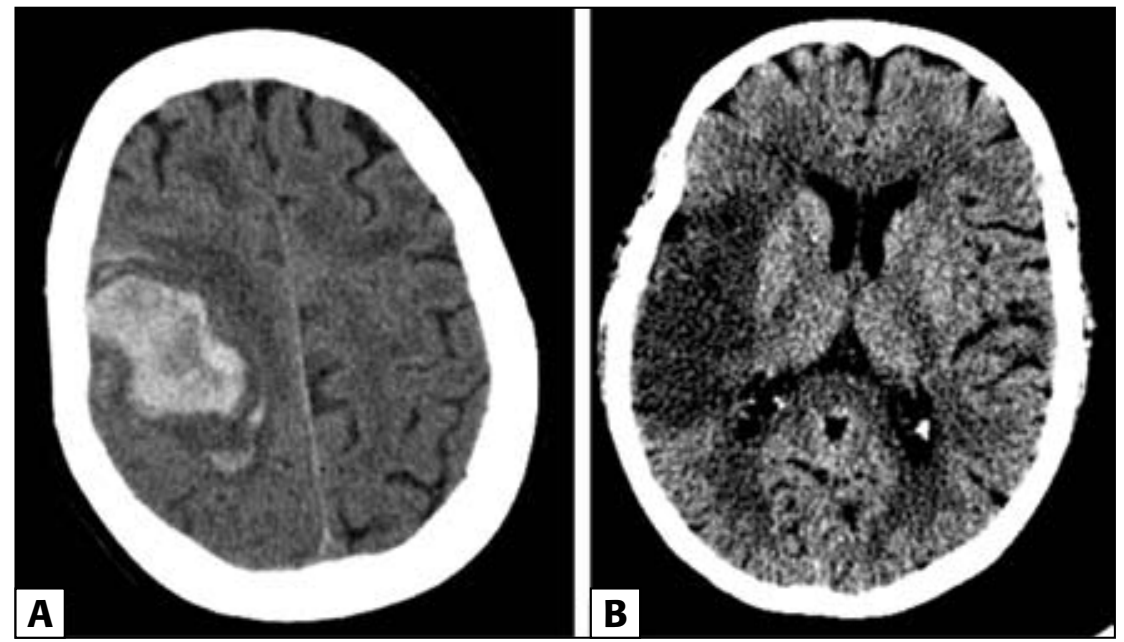

Figura 12

hematoma en la imagen A y un infarto en la imagen B.

c. Cortes axiales del encéfalo con una hemorragia en la imagen A y un hematoma subdural en la B.

d. Imágenes radiológicas normales en un corte axial medio del encéfalo.

15. Las imágenes de la figura 13 corresponden a una TC de cráneo en la que se puede observar:

a. Cortes axiales del encéfalo con la imagen típica de una masa tumoral.

b. Cortes axiales del encéfalo con imágenes compatibles con hematomas. c. Cortes axiales del encéfalo con imágenes de infarto agudo.

d. Cortes axiales del encéfalo con imágenes radiológicas compatibles con presencia de contraste intravenoso.

\section{RESPUESTAS}

1 b La técnica diagnóstica de elección depende de la situación clínica y de la sospecha patológica, que se determina a partir de la exploración física y la anamnesis del paciente.
La radiografía de abdomen en decúbito supino es, en general, la técnica radiográfica de primera elección en pacientes que consultan por dolor abdominal. Esta radiografía ofrece una visión global y permite una primera valoración que aporta información de manera rápida e incruenta de la cavidad abdominal.

La imagen de la figura 1 muestra una radiografía de abdomen en decúbito supino que presenta una importante distensión abdominal, y si se la compara con la imagen de abdomen normal, debe llamarnos la atención.

En este caso, en función del cuadro clínico del paciente, estaría indicada la realización de una TC.

La radiografía de abdomen en bipedestación demuestra la presencia de niveles que en la mayoría de los casos son indicativos de patología de intestino delgado, aunque también puede ser un hallazgo inespecífico sin relación con patología alguna.

\section{2 b La imagen de la figura 2} corresponde a una radiografía de abdomen con restos de contraste de bario en el trayecto intestinal, que tienen una traducción radiológica cercana al blanco, como corresponde al contraste que se está eliminando. Puesto que éste se halla en el intestino grueso, el paciente se habrá realizado
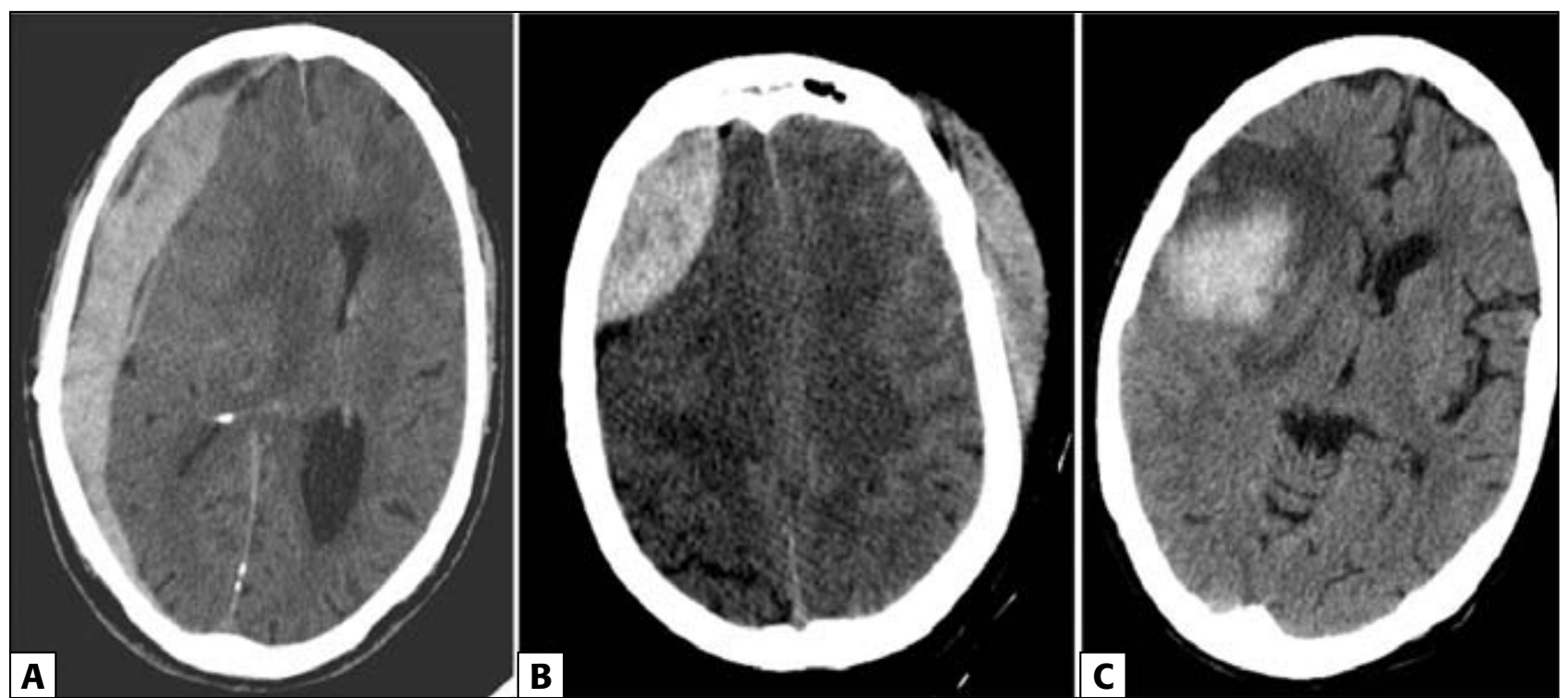

Figura 13 
recientemente una exploración con contraste radioopaco.

También observamos prótesis totales de cadera bilaterales que corresponden a la densidad metálica, que se traduce en el blanco intenso en la imagen radiográfica.

En este caso, la anamnesis del paciente hubiera informado de la reciente prueba con contraste baritado que, debido al periodo de eliminación de éste (unos 10 días), se mantiene en el tracto intestinal y dificulta, tal como se observa en la imagen, la visualización de las estructuras abdominales. En estas ocasiones conviene valorar la necesidad de la radiografía, teniendo en cuenta el resultado que se obtiene.

3 d Siendo la consulta por dolor abdominal una situación habitual en el servicio de urgencias, conviene repasar las alteraciones más importantes que se pueden presentar. En la entrega de Nursing correspondiente a la radiología de abdomen se mostraron diversas imágenes de situaciones patológicas usuales que, al compararlas con la imagen radiológica normal de abdomen, permiten al profesional de enfermería detectar las alteraciones más usuales, sean éstas más o menos graves.

El aire y su disposición en el abdomen es un elemento a valorar en la radiografía de abdomen e indica y caracteriza diversas alteraciones intestinales que se pueden observar en la radiografía de pacientes que acuden al servicio de urgencias por dolor abdominal.

La radiografía que se presenta en la figura 3 corresponde a una proyección de abdomen realizada con el paciente en bipedestación. Esta proyección está indicada para descartar la presencia de niveles hidroaéreos como los que se pueden observar en el epigastrio y el hipocondrio izquierdo de esta paciente.

Como siempre, teniendo en cuenta los antecedentes y la anamnesis realizada al paciente, y con la imagen radiográfica que se muestra, se puede sospechar patología intestinal.

La imagen muestra una ausencia de patrón gaseoso intestinal que indica una obstrucción.

4 b La consulta por ingestión de algún cuerpo extraño es una situación habitual en el servicio de urgencias.
Normalmente se trata de niños, sin que exista certeza absoluta de que la ingestión se haya producido o no. Para descartarlo y determinar la situación del objeto en el trayecto intestinal, inicialmente se realiza una radiografía toracoabdominal. Si el cuerpo extraño es conocido y radioopaco, se identificará localizado en algún punto del tórax o el abdomen. Si no se identifica o es radiolucente, se realizará una radiografía de tórax espiratoria para descartar obstrucción de la vía aérea. Hay que tener en cuenta que la localización del objeto depende básicamente de su densidad. Así, son fácilmente localizables objetos metálicos o de densidad elevada, y resulta más complejo identificar los que tienen poca densidad y, por tanto, su traducción radiológica no es contrastable en la imagen radiográfica. Para localizarlos en el espacio se puede recurrir a dos proyecciones, pero no suele ser necesario. Igualmente es rara la necesidad de realizar una TC.

En la primera entrega de Nursing dedicada a la radiología de urgencias se describió la misma idea pero en el caso de los cuerpos extraños u objetos incrustados o clavados en alguna región anatómica.

La figura 4 muestra cuatro radiografías de abdomen. En la imagen A, correspondiente a un niño (obsérvense las zonas de crecimiento óseo en las cabezas femorales), se observa, en la zona central del abdomen a la altura de L-5, una imagen lineal de densidad metálica.

La imagen B corresponde a una persona adulta. Muestra una estructura artificial con una porción más densa y otra más alargada, menos densa en la zona del ala pélvica derecha, compatible con un termómetro. En este caso puede hallarse fuera del cuerpo del paciente, en la mesa de exploración. Para determinar la posición exacta sería necesaria otra proyección.

La imagen $C$ corresponde a una radiografía de un paciente de corta edad realizada en bipedestación (obsérvese la cámara gástrica con un nivel hidroaéreo), con la presencia de un objeto de densidad metálica ligeramente a la derecha, a la altura de la L-5.
La imagen D es una radiografía de un niño. Muestra una imagen redonda de densidad metálica en la zona de la cámara gástrica. Además presenta un protector gonadal (estructura rectangular radioopaca en la zona de la sínfisis púbica).

5 d La figura 5 muestra dos imágenes con presencia de calcificaciones en el sistema uretral. La imagen A muestra una imagen de densidad cálcica alargada, en la zona del uréter izquierdo a la altura de L-5. La imagen B muestra igualmente una calcificación a la altura del riñón izquierdo. En ambos casos, para asegurar la posición del cálculo sería necesario completar el estudio mediante una pielografía.

Estas imágenes en un paciente que acude a urgencias con clínica de cólico nefrítico sugerirán la presencia de un cálculo en el uréter izquierdo (imagen A) y la presencia de una calcificación en el riñón izquierdo (imagen $\mathrm{B}$ ).

El 95\% de los cálculos de la vía urinaria son visibles en la radiografía simple. Sólo un 5\% son radiotransparentes, debido a que están compuestos de ácido úrico. Virtualmente el 100\% de los cálculos son visibles mediante TC.

La ecografía permite identificar si un cálculo condiciona la dilatación de la vía urinaria.

En otras ocasiones estas imágenes radiológicas pueden ser un hallazgo radiológico sin traducción clínica. Como siempre, la clínica del paciente y su exploración física determinan la importancia de la imagen radiológica que el profesional de enfermería visualiza en el servicio de urgencias.

6 c La necesidad de realizar una radiografía o una TC en pacientes embarazadas que acuden al servicio de urgencias no es extraña. Como norma general, las pacientes embarazadas no deben someterse a exploraciones como la radiografía y la TC que basan la imagen diagnóstica en la radiación ionizante, puesto que existe cierto riesgo para el feto, sobre todo en las fases iniciales de la gestación.

Sin embargo, si la situación clínica de la paciente requiriera, por riesgo vital de la paciente, la realización de las mismas, 
se llevarían a cabo intentando minimizar al máximo la exposición del feto a la radiación.

Existe la opción de indicar alguna otra técnica diagnóstica que no utilice radiación, siempre y cuando la resolución diagnóstica de cada caso lo permita.

Para evitar irradiar a pacientes embarazadas, si existe la posibilidad, se puede realizar prueba de embarazo antes de realizar la radiografía o la TC, siempre y cuando la situación clínica de la paciente lo permita.

\section{7 a La imagen de la figura 6} corresponde a una radiografía de abdomen con una alteración de la normalidad. Por tanto, al observar esta radiografía, el profesional de enfermería identifica una alteración con respecto a la imagen radiológica normal del abdomen que debe hacer sospechar algún tipo de alteración que, junto con la clínica del paciente y sus antecedentes patológicos, y otras pruebas complementarias, permitirán establecer un diagnóstico.

En la imagen se observa una distensión abdominal con aumento de densidad central sin gas intestinal, con probable obstrucción intestinal.

8 b La radiografía de tórax proporciona rapidez, accesibilidad e información crítica, de alto valor diagnóstico en el caso de pacientes en el contexto asistencial de urgencias. Es por ello una importante herramienta diagnóstica, de primera elección en muchas situaciones clínicas que se producen en urgencias. Una de estas situaciones clínicas que se pueden producir es la que se refleja en las imágenes de la figura 7, que muestran en todos los casos, en mayor o menor medida, la presencia de aire libre en la cavidad abdominal.

Esta imagen radiológica es característica (patognomónica) y se produce por la presencia del aire libre justo debajo del diafragma que, con el paciente en bipedestación, se desplaza hacia arriba observándose la característica imagen en media luna. Cuando se observa en el lado izquierdo, podría confundirse con la cámara gástrica, aunque la imagen es sustancialmente distinta.
El conocimiento del profesional de enfermería de urgencias de las imágenes radiológicas características de determinadas situaciones clínicas ayuda a minimizar el tiempo de resolución del diagnóstico y favorece tomar las decisiones terapéuticas adecuadas.

9 a La radiografía de tórax, tal como se ha indicado, aporta gran información sobre el estado del sistema cardiorrespiratorio del paciente, de manera rápida y poco invasiva. Por ese motivo es la primera exploración diagnóstica en pacientes que acuden al servicio de urgencias con sospecha de patología torácica. La radiografía de tórax está indicada en el estudio de dolor torácico agudo como complemento de la anamnesis clínica, del electrocardiograma y de los marcadores biológicos cardíacos.

Difícilmente, con una única radiografía se puede emitir un diagnóstico, excepto en aquellos casos clínicos que tienen una traducción radiográfica típica o característica que indican inequívocamente una alteración o patología.

La radiografía de tórax está también indicada en el contexto de urgencias en el caso de las fracturas costales y/o esternales, para descartar neumonías y sus complicaciones y patología pleural.

La TC se realiza en algunos casos por su alto valor predictivo, sobre todo negativo.

En la imagen A se observan infiltrados en el lóbulo superior derecho e inferior izquierdo. La imagen B muestra una condensación en el lóbulo inferior derecho. La C muestra una masa hiliar sospechosa de neoplasia. La D es una imagen de neumonía de lóbulo medio.

10 d Además de para diagnosticar, las técnicas de diagnóstico por la imagen son útiles para realizar tratamientos. Algunos ejemplos de esto son la localización de drenajes y colecciones intraabdominales guiadas por ecografía o por TC, el diagnóstico y la embolización de hemorragias de todo tipo (digestivas, pulmonares, etc.); también se utiliza para desenvaginación intestinal en niños.

11 c Las imágenes de la figura 9 muestran el aspecto radiológico característico del neumotórax.
La imagen A muestra un neumotórax en la parte izquierda del tórax que desplaza completamente el parénquima pulmonar hacia el lado derecho. La imagen B muestra un neumotórax en la parte derecha con una imagen redondeada más densa en la parte baja del mediastino que corresponde al parénquima pulmonar colapsado. Obsérvese que la presencia de un neumotórax se puede identificar por la densidad totalmente negra, sin las tonalidades grises que corresponderían a la suma de aire y vasos que serían visibles en una radiografía de tórax normal y que en este caso no se observan por el desplazamiento provocado por la presión del aire dentro de la cavidad pleural.

En ambos casos la clínica del paciente será de disnea, dolor, taquicardia y ansiedad.

Ésta es una de las situaciones clínicas habituales en urgencias en las que la detección y el reconocimiento de esta imagen por parte del profesional de enfermería pueden favorecer acelerar el tratamiento y la resolución de la situación.

El neumotórax es una complicación frecuente de los traumatismos torácicos.

12 d Las imágenes de la figura 10 muestran diversos ejemplos de exploraciones radiológicas que se han realizado con objetos y elementos que deberían haberse retirado y que dificultarán su visionado y provocarán, en un elevado porcentaje de ocasiones, la repetición de las exploraciones, con el consiguiente aumento de exploraciones y de exposición a la radiación para el paciente. En el caso de la TC esto se agrava, puesto que los artefactos provocados por los objetos pueden confundir e insinuar alteraciones no existentes.

En mujeres en edad fértil hay que descartar la posibilidad de embarazo previamente a la realización de las exploraciones y extremar las medidas de radioprotección en caso de realizar exploraciones portátiles en el servicio de urgencias. Igualmente, el hecho de coordinar con el servicio de radiología el traslado y la realización de las exploraciones agilizará y reducirá los tiempos del proceso. 
En la figura 10, en A y C se puede observar una imagen de densidad metálica que corresponde a las partes metálicas del sujetador. En la imagen B, se observan colgantes, y en la imagen D se puede observar diversas estructuras metálicas (agujas de pelo, pendientes, colgante, prótesis dentales) que en todos los casos dificultan el diagnóstico de posibles lesiones.

13 a Las indicaciones de la TC dependen de la situación clínica del paciente. Es fundamental la administración de contraste intravenoso en estudios de tórax y abdomen, y para ello el paciente debe tener una función renal conservada y no presentar antecedentes alérgicos al contraste yodado.

En los pacientes politraumatizados la TC permite una valoración de lesiones de cráneo, columna, tórax y abdomen, con mayor detalle y precisión que otras modalidades diagnósticas. Sin embargo, en el caso de la TC hay que considerar elementos como la inmovilidad del paciente, la necesidad de un tiempo (cada vez más corto) para la adquisición de la imagen y que no se puede manipular al paciente durante la exploración.

En pacientes hemodinámicamente inestables se requiere una mínima estabilidad hemodinámica para poder trasladar al paciente con garantías de seguridad.

14 b El estudio del encéfalo, en pacientes con clínica de accidente vascular cerebral, es una de las situaciones habituales en el contexto asistencial de urgencias.
Normalmente las imágenes obtenidas mediante TC de cráneo son altamente resolutivas y ofrecen la capacidad de un diagnóstico diferencial de una estructura anatómica vital como es el encéfalo.

En la figura 12, la imagen A muestra un corte axial a nivel medio del encéfalo con la presencia de un hematoma intraparenquimatoso agudo en el hemisferio derecho. La imagen B muestra un infarto cerebral también en el hemisferio cerebral derecho.

15 b La figura 13 nos muestra en este caso imágenes de hematomas. La imagen A corresponde a la imagen radiológica clásica de un hematoma subdural agudo. La sangre se colecciona en el espacio subdural adoptando la imagen típica en semiluna. La imagen B corresponde a un hematoma epidural agudo frontal derecho. Se localiza en el espacio entre el hueso y la meninge más externa (la duramadre) y clásicamente adopta una morfología cóncavo-convexa. La imagen $C$ corresponde a un hematoma intraparenquimatoso.

En las tres entregas dedicadas a urgencias se ha mostrado la importancia de las técnicas de diagnóstico por la imagen, que constituyen un elemento cotidiano utilizado para la resolución de situaciones clínicas en pacientes que precisan una toma de decisiones rápidas y seguras, como es habitual en urgencias.

Las exploraciones diagnósticas ayudan y complementan la información que el profesional de enfermería puede obtener mediante la anamnesis y la exploración física del paciente. Primero la radiografía, así como la ecografía o la TC, permiten llegar a un diagnóstico certero y planificar los cuidados adecuados para el paciente de urgencias.

\section{BIBLIOGRAFÍA}

Artigas J, Martí M. Manejo radiológico del paciente politraumático. En: Radiología esencial. 1. ${ }^{a}$ ed. Madrid: Panamericana; 2010. p. 1769-84.

Brainsky A, Fletcher RH, Glick HA, Lanken PN, Williams SV, Kundel HL. Routine portable chest radiographs in the medical intensive care unit: Effects and costs. Crit Care Med. 1997;25(5):801-5.

Colyar M. X-rays in emergency settings. Adv Nurse Pract. 2004;12(1):22-5.

Eisenberg RL, Denis C. Sistema respiratorio. En Radiología Patológica. Barcelona: Mosby YearBook; 1992. p. 21-60.

Fishman J, Primack L. Thoracic imaging in the intensive care unit. Applied Radiology. 2005:8-17.

Fleckenstein P, Tranum-Jensen J. Tórax. En: Bases anatómicas del diagnóstico por la imagen. 2. ${ }^{\mathrm{a}} \mathrm{ed}$. Madrid: Elsevier; 2002. p. 274-277.

Kelly-Heidenthal P, O'Connor M. Nursing assessment of portable AP chest x-rays. Dimens Crit Care Nurs. 1994;13(3):127-32.

Pedraza S, Puig J. Traumatismo craneal y maxilofacial. En: Radiología Esencial. 1. a ed. Madrid: Panamericana; 2010. p. 1163-1172.

Pedrosa C, Casanova R. Tórax. En: Diagnóstico por la imagen. Madrid: McGraw-Hill Interamericana; 2001. p. 27-160.

Correspondencia: Jordi Galimany Masclans Departament d'Infermeria de Salut Pública, Salut Mental i Materno-Infantil Campus de Bellvitge. Pavelló de Govern. 3ra planta. C/ Feixa Llarga s/n. 08907 L'Hospitalet de Llobregat. Barcelona. España

Correo electrónico: jordigalimany@ub.edu 